\title{
Framing children through observation practices: using art theory to re- think ways of looking at children.
}

Christina MacRae

Manchester Metropolitan University, All Saints Building,

All Saints, Manchester, M15 6BH, England

c.macrae@mmu.ac.uk

\begin{abstract}
This paper looks at methodological questions that are raised through the practice of observation to consider how researchers 'keep an eye on the world', and particularly how early years practitioners keep an eye on children. Drawing on notions of perspective in art history and theory as methodological resources it asks questions about the frames through which children have been conventionally seen in both research and Early Years Settings. In particular I have chosen to focus on the Target Child Observation System, as it was the system that I was first trained to use both as an Early Years Teacher and as a researcher. By referring to perspective as a method to represent what is observed, the paper contrasts two different models of perspective. Alberti's use of the window and grid to project the observed is contrasted with Brunelleschi's mirror play. Questions are raised about how observation as procedure acts to limit vision by organising the gaze. Brunelleschi's demonstration of perspective can be useful in order to remind us of ways in which the objects of our gaze might escape verification through observation.
\end{abstract}

\section{Introduction}

Linear perspective drawing is a technique for representing three dimensional space on a two dimensional plane which imagines the self to be a spectator behind a window who takes the world's measure with the eye and with the eye alone. Keeping an eye upon the world, the spectator now makes sense of the world as a spectacle for observation, measurement, and calculation (Romanyshyn, in Brien, 2005).

In this paper I shall consider how I, as a researcher, 'keep an eye on the world' and specifically how my eye is kept on the children that I observe. Calling on notions of perspective in art history and theory as methodological tools, I ask how they might help me to ask questions about the frames through which children are conventionally seen in research and early years teaching contexts. Rather than looking harder or more closely, Patti Lather (1993, p. 675) urges us to look at "what frames our seeing" as an incitement to see "spaces of constructed visibility" that produce relations of power and knowledge. The aim here is to pay close attention to how techniques of observation both frame children, and construct visibility with particular effects in relation to power and knowledge. I focus particularly on the techniques of observation schedules that organise the observation of children in procedural ways. I have chosen to focus on the Target Child system of observation. This is a system developed in the U.K. in the 1970's as part of the Oxford Preschool Research Project and it has continued to be used by researchers and by teachers alike (some examples include Anning \& Edwards, 2006; Sylva, et al. for the EPPE project, 2004; Adams et al, 2004). I made this choice because it was the system that I was expected to use when I was training to be a teacher. In large part, my teaching practice consisted on regular completion of Target Child observation sheets. When I later became a 
researcher, it was this observation procedure that I was again expected to use. The Target Child observation schedule consists of a gridded sheet of paper where observations are meticulously timed, recorded and coded. The horizontal lines divide the sheet into equally distributed rows for each minute of observation. The primary horizontal column is where the actions of the target child are recorded (minute by minute). The next column records the direction of conversations flow between the target child and others, and subsequent columns are for later coding according to type of activity and size of social group in which it took place. I am aware that for some this as an outdated system for observing children; however it remains a dominant model if in modified formats (Anning \& Edwards, 2006). I concerned that even where the gridlines of the Target Child's observation sheets are removed, and less demarcated observation sheets are used, the disciplinary effects of the grid will continue to haunt our practice. While more recent trends are towards documenting the children's 'learning journeys', I am concerned that such shifts may be surface deep until serious thought is given to the theoretical assumptions that lie behind traditional observation techniques.

In this paper I would like to dig a little deeper into the theoretical connections that the practice of observation as a drawing technique and the practice of observation as a technique for knowing the child might share. This connection will take an archaeological journey into the origins of perspective in order to establish the deep-seated links between the deployment of perspective in drawing and in research methods. The paper argues that to look at observation in radically new ways we need to explore more seriously the foundations of observation as a research tool. This means looking at the history of observation in art. Running alongside the dominant model of perspective for drawing has also been an alternative version that goes back to the so-called origins of perspective. In the paper, Alberti's version of perspective through the use of the window and grid to project the observed, will be contrasted with Brunelleschi's play on projection through the use of mirrors. Similarly in the social sciences, while natural science approaches to observation have generally been employed to record the world of the visible, the alternative approach to perspective offered by Brunelleschi can be used to de-stabilise what we see rather than to shore-up the already visible.

Contrasting these two methods raises questions about how observation as a procedure forecloses what can be seen by organising the gaze and how this might perpetuate a belief that children occupy worlds that we can "define, explain and know" Cannella \& Viruru (2004, p. 79). I argue that Brunelleschi's demonstration of perspective can be useful in order to remind us of ways in which the objects of our gaze might escape verification through observation. His experimental play with mirrors can also be used to think about how our gaze is returned to us through the observed, making us aware of how seeing transforms both the seer and the seen (Elkins, 1996, p.12). I will offer a critique of mimetic and veridical perspective that can be detected in child observation techniques and in particular the Target Child System. These approaches to observing children bear traces of a simplified version of perspective and point of view, even where they claim to have moved away from naturalistic and objective methods. Beginning with a brief historical look at perspective in order to first outline the dominant model perspective as proposed by Alberti, I will go on to show the connections between this method of recording the world with child observation schedules. Later I will introduce Brunelleschi's alternative approach to perspective as an incitement to think differently about observing children. 


\section{A short history of perspective according to Alberti}

One sees sensibly and rationally according to a science that is called Perspective, arithmetical and geometrical (Dante in Baxendale, 1972, p. 124).

The origin of perspective is popularly associated with the Italian artist/architect Brunelleschi's painting of a baptistery in Florence in 1413. The rules of perspective were later codified by his contemporary, Alberti in 1435, in a treatise called Della Pitturu (On Painting). Alberti called his linear perspective system Construzione Leggitima ('The Best Method'), also known as 'artificial' or 'scientific' perspective. Before Alberti consolidated the rules of perspective, systems based on Euclidean geometry were employed using strategies such as proportionate diminishing size of horizontals or squares (Dubery \& Willats 1972). What Alberti did, with reference Brunelleschi's painting, was to systematize projection onto a picture plane by means of plan and elevation. According to Panofsky this elevated art to science (1991, p. 66). It enshrined as foundational, a fixed point from which to measure in order to accurately (re)present what is seen from that vantage point.

Fixing the view point of the painter gives a distance which can be measured; "know that a painted thing can never appear truthful where there is not definite distance for seeing it" (Alberti, 1966, p. 57). Alberti described the lines (or rays) from the eye to the object to be drawn as threads, which could be imagined as a veil forming a cone/pyramid of vision from the looking point to the object. This cone or triangle of vision is at the heart of three-dimensional projection. As in surveying, the line at a right angle to the eye is all-important, with the vanishing point at the centre, from which space is measured and calculated (Cosgrove, 1985, p. 48).

Alongside this codification of the method by which to best capture the visual world, Alberti also demonstrated the methodology in more material terms. In order to assist the artist he suggested actualising his 'veil of threads' by physically attaching threads from the object being painted to the canvas in order to map the object accurately in two dimensions. He devised another graphic technology to project the window scene that the painter wished to represent onto the picture plane. Alberti's grid, or window, is a device that assists in the accurate mapping of the picture; it consists of a frame, divided into a grid, with a small viewing circle in front to fix the eye. I foreground Alberti's grid here as it has similarities to the grid of the Target Child System where the use of gridlines is used once again to assist in accurate mapping of reality.

Alberti's window

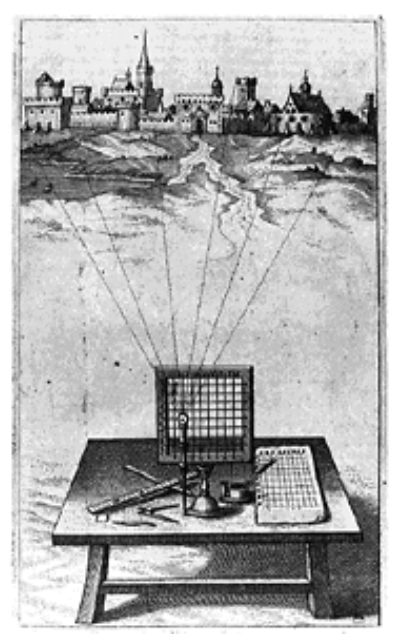


Other lens-based optics also demonstrate how graphic technologies also fixed the eye, hence giving it primacy. Both Jonathan Crary (1998), and David Hockney (2001) explore the specific effects of the Camera Obscura on visual practice, producing a photographic mode of representation that predates the photograph by many centuries. Hockney investigates the way that this "archetype" of the "ideal of mimesis" came to dominate visual representation.

The power of the apparently 'real' in photographically based media is huge - as is the power of what is seen as 'scientific'. If it's done by instrument, without human intervention, if it's precisely measured, if it's set up to declare scientific objectivity, it demands to be trusted (Kemp in Hockney, 2001, p. 248).

So although visual territory may have shifted radically over time, there are aspects of sixteenth and seventeenth century realist painting that can be associated with contemporary photographed images in the way that they "do not seem to be statements about the world so much as pieces of it" (Sontag, 1979, p. 4). This ideal of photographic depth and detail (captured in Dutch realist painters like Vermeer and Van Eyk) is reminiscent of the slice-of-reality depth that is invoked in the 'thick' description of the ethnographer (Geertz, 1993). In this sense one can read the modern ethnographic text as a photograph in its claims to represent the real (Denzin, 1997, p. 44).

Furthermore, single-point perspective (inspite of other techniques) remains as a dominating model that leaves its traces even in models of sight that apparently seek to undermine its foundations. It naturalises vision, by making seeing the foundation of knowledge. Vision is at the heart of certainty and it "goes without deliberation" (Trinh, 1991, p. 25). What is seen and what is known become conflated; "looking, seeing and knowing have become perilously intertwined" (Jenks, 2005, p. 154). The problem lies not with vision itself, but rather with its naturalised and totalising claims. Leonardo De Vinci has often been quoted as saying that perspective is nothing more than the seeing of an object through a sheet of glass, on the surface of which is traced all the things behind the glass. This could just as well be describing observation as a straightforward method of revealing reality. Jenks (2005) picks out three central characteristics of observation as metaphor: the finite and visible nature of social phenomena; clear-sightedness; and a particular visually constructed relationship between the subject and the phenomena studied. The emphasis on what is visible to a detached observer (morally and politically suspended), leads paradoxically to taking things at 'face-value', a 'commitment to surface' (p. 161), rather than depth. And with the focus on the field of vision lies another paradox: "positivist instructions for 'good seeing' are essentially directives for partial sight" (p. 161). This is because the cone of vision at the heart of Alberti's 'best method' is a narrow and positioned view. What it reveals is just a fraction of the full field of vision, a partial view cut from the totality (Bryson, 1988, p. 100). I want to argue that using a framing device such as the Target Child to organise observations of the child will similarly produce a narrow view that is unable to take account of what is out-of-frame.

A final and crucial paradox lies in the particular relationship established between the observer and the observed. Separating the viewer (self) and viewed (other) in a relationship defined by distance, has the effect of simultaneously splitting the subject and object and making them contingently implicated. In the same breath, "perspective creates distance between human beings and things [ ]; but in turn it abolishes distance by, in a sense, drawing this world of things, an autonomous world confronting the individual, into the eye" (Panofsky, 1991, p. 67). Alongside this is the contradiction that lies at the heart of humanism: the emergence of 
renaissance man simultaneously with something that negates that very humanism through its delineation of space that freezes time and motion (Damisch, 1995, p. 45).

\section{The methodological entanglements of observation in art and research methods: observation as metaphor}

I now move on to explore more directly how the ideal of observation in art history is entangled with the language of research methods. Alberti's use of surveying and triangulation to project an accurate picture of the world can be detected in the validity discourses in research methods (eg. Hammersly and Atkinson explicitly use this mapping analogy as a source of validity in ethnographic research methods, 1995, p. 231). In this paper, however, it is the effects of using the grid as a technology for child observation that I am interested in. The Albertian grid will become a metaphor for an "empire of structure" (Deleuze, 1988, p. 14) that frames and organises how we see children. Like Delueze and Guttari's striated space (1988, p. 474), it produces "sedentary space, space that is coded, defined, bounded and limited" (St. Pierre, 1997, p. 369). The grid claims to represent the child as a visually legible form inside the frame, but it simultaneously has the effect of constructing and containing the space that the child inhabits. This act of construction is disguised and the grid presents us with the child "in an already composed state, already articulated" (Foucault, 1994, p. 252). Operating through the norm and the rule, within this process of observation 'the' child is both already produced and being produced at the same time. At the same time it positions the viewer. Here we should pause to consider the double meaning of observation: both in the sense of seeing, and in the sense of observance of regulations (Crary, 1998).

Observation as procedure promises to replicate the seen. It reflects, as mirrors do, but it disguises these reflections as laws of nature, as a translation "between nature and art, setting out, with nature, the causes of nature's phenomena regulated by nature's laws - how the likenesses of objects adjacent to the eye converge with true images to the pupil of the eye" (Leonardo Da Vinci, in Baxendale, 1972, p. 119). Like Jenks, I have used observation as a metaphor for method as a way to interrogate its privileged place as positivist research tool.

As a metaphor for method or technique within the social sciences or cultural studies 'observation' drags behind it an excess baggage of ontological and epistemological assumptions, albeit unexplicated, that can direct us to the origins of 'our ways of seeing' through modernity (Jenks, 2005, p. 158).

According to Jenks, while a critical engagement with the complexity and paradox surrounding contemporary visual practice has long been a topic for fine art, and even psychology, it has been late coming to social theory $(2005$, p. 162$)$. With its insistence on value-free method, of which observation is a crucial technique, theory masquerades as generality. Just as sight is always partial, Jenks draws our attention to the necessarily partial nature of socio-cultural theory, in the sense that what the researcher chooses to look at is "always chosen in relation to some set of interests" (p. 162). In order to maintain authority, a method must be externally located and it must be observed (in the sense adhering to procedure). This is how method disciplines us, in the name of validity. Trinh talks about the rules of anthropological authority and the way that in the process of fixing meaning, not every explanation is valid. This is where the 'expert' comes in (for my purposes in the form of ethnographic researcher or teacher), using method to legitimate what is reliable knowledge (Trinh, 1991, p. 45). What we select to look at becomes legitimated through the method employed to order and classify the fragments of reality that we collect. It is a framework that insists we edit out the messy bits, the things we do not expect or cannot make 
sense of. While multiple-viewpoints may trouble an overarching version of reality, they can also be subsumed as simply more slices of reality to collect.

\section{The Target Child Observation Schedule as a space of constructed visibility: legacies of the grid} Truth is inseparable from the procedure establishing it...but what constitutes procedure? ... The process is that of seeing (Deleuze, 1988, p. 63).

To observe, then, is to be content with seeing - with seeing a few things systematically (Foucault, 1994, p. 134).

I now turn to the place of observation specifically in relation to the professional practice of early years teachers and researchers and the way that observation is a way of looking that is mediated by procedure. I would suggest that from her professional framework, the early years teacher/researcher observes "within a prescribed set of possibilities, as one who is embedded in a system of conventions and limitations" (Crary, 1998, p. 7). I intend to explore how observation techniques function as windows onto the world, that construct what is visible, and hence, produce a specific regime of knowledge about the child. Foucault provides a backdrop for what started out as a genealogical approach which "retraces the system of 'dependencies' of discourse" and "reconstructs a history which accounts for how a discourse or practice emerged, for the conditions of its emergence and constitution (discursive, material and historical) and how it comes to be what it is at present" (Walkerdine, 1984, p. 104). I'd like to develop Valerie Walkerdine's account of the central role of observation in producing 'the child', both as an object of science and of the apparatuses of normalisation, in relation to the Target Child observation schedule. As previously mentioned this particular way of observing children was one that I was inducted into both as a trainee teacher and an early career researcher. This has meant that I have been able to look back at my own observation sheets, and even compare the messy unedited ones that I made during the flow of classroom life, with the neatened up versions that I presented to my tutors in my teaching practice file.

The Target Child observation system was first detailed in the book Childwatching at Playgroup and Nursery School, (Sylva, et al., 1980). Here systematised observation is presented as a means to uncover truths and to counter intuition and dogma, because "hunches and received wisdom serve well as everyday guides but they quickly acquire halos unless put regularly to the test of objective scrutiny" (p. 3). Thus the procedure of child observation is employed as a method to break with habitual knowledge, a way to make knowledge fresh and firmly rooted in the here and now. But by at the same time appealing to the present and to the production of new knowledge, the authors invoke the past. They employ the rhetoric of empirical procedure: the foundation of 'objective scrutiny'.

The research we favour should take place in every pre-school and follow the age-old canons of exploration and inquiry. First, specify the question. Then make clear the objective procedure for its answer. Finally, collect the information and interpret its meaning in the light of the original query. (Sylvia et al., 1980, p. 3).

A classical discourse of natural history is invoked in order to carry out a structuring of the space in which a particular child in the here-and-now can come to be known afresh. The word 'habitat' is deployed as a site both of long-standing knowledge and of fresh insight. The use of the term also collapses categories of child and animal. The authors explicitly compare the procedure of the child observer with that of the naturalist, a procedure marked by detailed, 
formalised and minute-by-minute note-taking; field-notes are then pored over and finally coded and quantified. The child-watcher is advised to "crouch sideways on to the child, but not directly facing him [sic]" and to "try avoid meeting his gaze" (p. 230).

The authority of knowledge produced about the child through procedure lies in its claims to be naturalistic. In this case observation is used to appeal to the legacy of natural history as a means to create the ideal environment for children to grow to their best potential. The method "has been stolen - in a respectable and scientific way - from people who study animal behaviour, and is a far cry from casual watching" (Sylva, et al., 1980, p. 229). The tactic of appealing to the methods of natural history is employed to counter the scientific discourse of the system and the rule. Yet at the same time this is a highly contradictory strategy, since the 'naturalistic' knowledge produced through observation is subjected to classification through precisely the procedure of rule and system. However, because this ordering process is founded on the "nomination of the visible" it has an "air of naiveté" about it. This simplicity means the order arrived at seems "obviously imposed by the things themselves" (Foucault, 1994, p. 132).

The Target Child observation focuses' on a specific child; fellow members of staff must be aware that you are undertaking an observation and therefore should not intervene in the situation unless the child might be endangered. The observations are usually 10 minutes long, although as one becomes more expert 20 minutes is recommended. As the observation is carried out on a recording sheet divided into minute-by-minute slices of watching, you are advised to wear a watch with a second hand in order to ensure that you are on time. For each minute slot there is a column to record a verbal description of what the child does (the activity record column). The next column consists of the language code, where the direction of conversation between child and others is recorded, and a final code is the social code that records what social grouping the activity takes place in, noting whether a child's activity was solitary, in a pair, in a small group, or in a large group.

The secondary stage of filling in the grid is to impose an analytic framework on the first-hand observations. The authors suggest first you should look at the observation and divide it into "coherent" spells of activity, or themes of activity. At the end of each theme you draw double lines across the page, so that you can see at a glance where one theme ends and another begins. Here the minute-by-minute frame has been superseded by the length of time that themes take. At this point each minute of observation can be coded according to the what is being researched, for instance level of involvement, or what type of task the child was engaged in. If the data was being coded according to nature of task the categories might consist of headings such as art, pretend, problem solving. The coded and quantifiable recording sheets allow the teacher to ask different questions about the activity of a child, such as how long children concentrate on activities and what factors might sustain or inhibit this. The procedure acts, as do more developmentally oriented observations, to demarcate the facts of what occurred from the subsequent interpretation of these facts. Because it separates out the observed behaviour from the analysis it claims to "make explicit its ways of filtering and interpreting" (Sylva, et al., 1980, p. 230). 


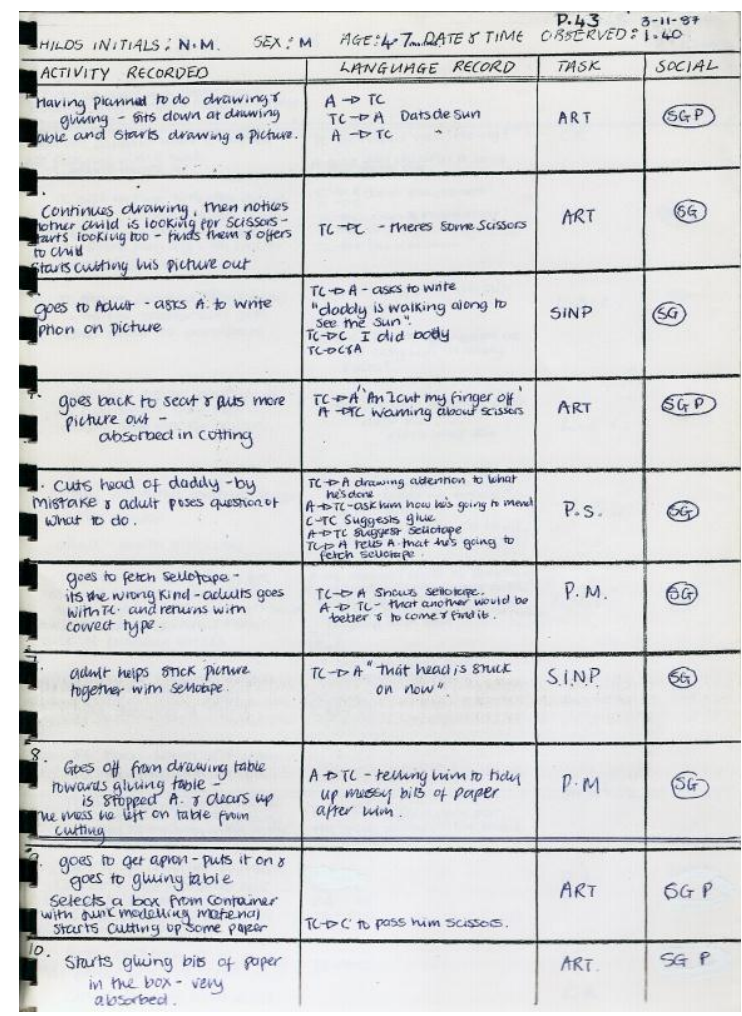

A copy of one of the completed Target Child sheets from my teaching practice file, 1987.

The formalised tracking sheet demarcates itself from more casual observation notes through a series of devices; the grid layout of the pre-drawn sheet requires in turn that you clock-watch at the same time as watching your target child. You are also reminded to maintain a detached and fixed position from which to focus on detail and to describe this view graphically. This constructs what Deleuze and Guttari refer to as striated space (1988, p. 474), a space that "has been carefully and conscientiously timed and placed" (St. Pierre, 1997, p. 369). The grid provides a neutral 'frame' in which to record the facts. At the top the child's name and sex are abbreviated into initials. The age of the child and the time and date are also recorded numerically. This indicates efficiency and economy of information so that only what matters is visible on the sheet. The distance between the observer and the object of observation is captured both through the reduction of names and codes into capitalised initials, and through the rigid order of the page. The primary grid lines give equal weight to each minute, while the secondary double lines across the page delineate themes with clear beginnings and endings and are unambiguous. All these graphic signs underscore the gravitas of these "respectable and scientific" records (Sylva, et al., 1980, p. 229), but the effect of the grid is to create "a sedentary space, space that is coded, defined, bounded, and limited" (St. Pierre, 1997, p. 369).

Having emphasised the graphic boundaries of the page, I shall now turn to the effects that such divisions create in terms of marshalling a framework for seeing. In the Target Child method, the observed becomes recorded evidence of what happened. At the outset there is a simplistic assumption that what is seen is able to accurately represent what took place. This raises many questions in my mind. Can you really 'see' what happens: a person's actions are complex and harness all the senses, haptic, touch and even sometimes smell. To what extent can an observer see this, and further to what degree of accuracy can this seeing be translated by words? Already one is watching in order to see activity rather than to see in general; so by looking at action, one 
risks ignoring other aspects of what is visible to the eye. Furthermore, it is the target child's actions that are seen; what other children/adults do is only recorded in relation to the activity of the child. So from the outset what you see is already framed; you will see an individual child acting on the world, and it is the chronology of action that is isolated and recorded; the observer sees "within a prescribed set of possibilities" (Crary, 1998, p. 6). With the Target Child method there is an underlying concern with how long children sustain themes of play and with what it is that sustains their interest or, conversely, brings the play theme to an end. This specific concern with play bears traces of the continuing construction of play as the site of naturalised and progressive learning. Here observation is activity (play) oriented at the outset, before coding has begun. Inevitably observation schedules are repeated; each performance ensuring the reproduction of such categories in subsequent observations. In this way each coding can be seen to leave sediments in the frame of seeing for prospective observations. The grid constructs a space that is ordered according to its own interests; but because it is filled by a nomination of the visible, processes of interpretation appear to be secondary rather than primary. The observer, in turning events into text produces data severed from the "communication of specific persons" (Clifford, 1988, p. 39). And just as the ethnographer colonises its subjects with cohesive intention, the teacher/researcher observer transforms the "ambiguities and diversities of meaning" of any recorded event into an "integrated portrait" (p. 40). Thus, with observation at the heart of the process, children are colonised, because "we have created them as psychological beings whose worlds we (as adults) can define, explain, and know" (Cannella \& Viruru, 2004, p. 79).

In practice, however, failures take place on both sides of the frame. As both teacher and researcher of young children, I have long struggled to discipline myself into fixed ways of seeing. The observations that I have made have refused to be contained neatly inside prescribed systems of observation: I don't have time to write what I see; my seeing is continually thwarted by my frantic scribbling as I make notes; I am distracted by the out of field world.

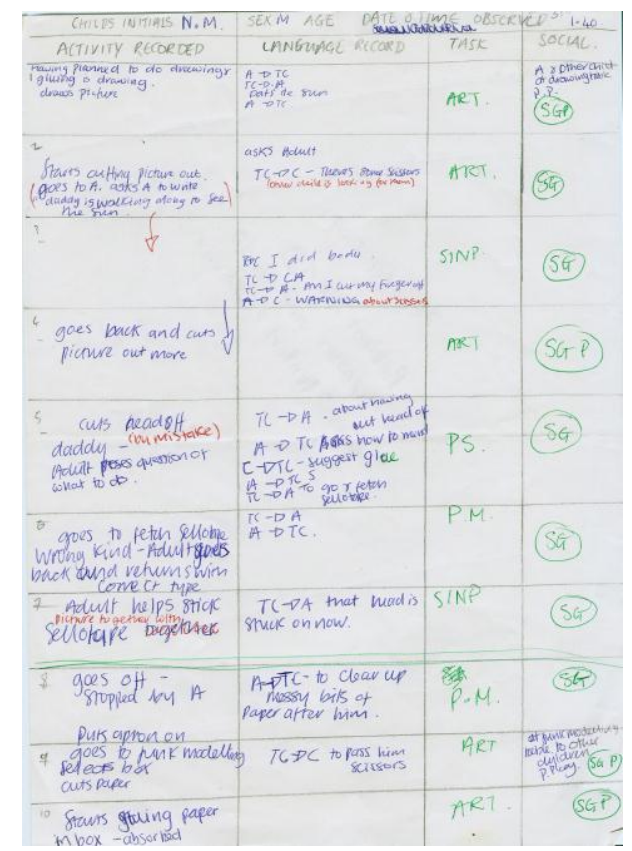

The 'messy' classroom version of my Target Child observation, before I re-drafted it, editing out the inconsistencies and confusions.

The finished sheets might look tidy, but they gloss over a subtext of ongoing failure to observe procedurally and with accuracy. On the other side of the frame, the child, as the object of the 
gaze, does not always fit into the organised space of observation. When I observe children at play I can't decide which categories to fit the data into, or when themes of activity begin or end. The very complexity of lived experience defies orders and categories. It is these failures that are all too easily overlooked. Whilst recognising that classifying and categorising may inform us about child outcomes and contribute to what Dahlberg et al have termed "a discourse of quality" (1999, p. 92), it is important to attend to the effects that this organisation has on the way we create knowledge about the child. These include the use of 'context' as an explanatory variable, as well as an individualistic orientation that focuses on "individual outcomes and relationships" (p. 100), and the reproduction of normative conceptions of child development ( $p$. 146).

\section{Thinking outside the box: mirror play}

In order to think beyond the enclosure of grid, I propose to turn to another model of perspective that in contrast to the grid makes explicit its failure to contain. This model operates in Brunelleschi's original painting from which Alberti then developed his system. While Alberti dedicates his treatise on perspective to Brunelleschi, he does not actually describe the famous painting that is popularly credited with the 'origin' of perspective. However, Manetti, Brunelleschi's biographer, gives a detailed account of this 'discovery' (Duberry \& Willats, 1972, p. 53). Brunelleschi's breakthrough is in the form of a small painting of the octagonal Baptistery in Florence. The picture is thought to have been painted as a mirror image, and it is unknown if it was painted directly on top of the polished silver panel (literally traced out onto a reflection), or was painted with the aid of projected geometry. Alberti's account focuses' on the way procedure organises the framed view, and the accuracy of the representation. This emphasis on accuracy is echoed in Manetti's account where he describes the effects of viewing the painting: "it seemed that one was seeing truth itself" (Damisch, 1995, p. 116).

There are, however, other ways of reading this story where the importance of the mirror plays a greater role. Damisch (1995), paying attention to the detail of Manetti's account, provides a counter history that puts the play on mirrors at the centre of the story, and further claims about the role of mirrors in this event have tended to be suppressed. Brunelleschi created a unique way to view the painting. He made a cone shaped aperture at the back of the picture and he then "directed that the spectator, holding the picture in one hand, should look through the aperture [ ] to a mirror held in the other hand" (Duberry \& Willats, 1972, p. 52). The viewer was directed to stand in the place that the painter originally stood, and to view the picture facing the baptistery itself. From this vantage point, the picture 'copy', could be compared directly with reality. However, what the viewer saw was not the painting itself, but the reflection of it on the mirror held in front of the painting held back-to-front.

Brunelleschi's experiment

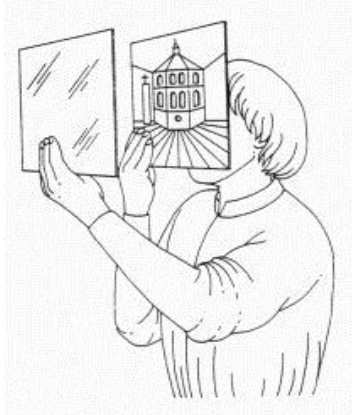


Damisch places emphasis on the experimental nature of this viewing procedure. He is interested in the way that by physically demonstrating the relationships between viewer and viewed, the viewing procedure actually acts to reveal the limitations of mathematical perspective. The experiment demonstrates perspective as rule, a rule that can be replicated through repetition of the experiment. However, the viewing procedure insists on physically placing the viewer at the same fixed point of the painter's eye. And by viewing the picture through a hole pierced through the vanishing point, one's own eye is projected into the vanishing point of the reflected picture. So it is this mirror play that provides an alternative way of looking at the method that the experiment simultaneously demonstrates.

Foucault famously deconstructs Velasquez's Las Meninas in terms of a play on the impossibility of a centric self as projected through perspective; the way it "makes us look ourselves in the eye, impossibilities notwithstanding" (Stronach, et al., 2007, p. 194). In Las Meninas the mirror acts as a "metathesis of visibility" (Foucault, 1994, p. 13). In his book "The Origin of Perspective", Damisch explicitly develops this idea further in relation to Brunelleschi's peep show. A peep show that at the same time as projecting a realist three-dimensional image of the Florentine baptistery also has the effect of allowing you to see your own eye reflected back at you at the picture, at the vanishing point of the picture. This reflected eye of the ' $\mathrm{l}$ ' is surely more in tune with a surrealist attitude, than a vision of reality. In this sense it fulfils the transformative task of interrogating the nature of 'seeing' and 'seen-ness' as advocated by Jenks.

Trans-formation is not a gathering of the world through vision, it is a re-ordering of the world within vision (Jenks, 2005, 169).

The reflected eye acts to prevent this ordering as naturalised perception, as a universal truth, and imbues Brunelleschi's painting with the uncertainty of partiality. At the same time as it's logic restricts vision, it simultaneously creates an opening, literally through the painting. It is a theme taken up by the modernist artist, Lucio Fontana, who used holes and fissures on the canvas to create an 'infinite dimension'; "I did not make holes in order to wreck the picture. On the contrary, I made holes in order to find something else" (Fontana, 2006). It is through this generative play and experimentation with the nature of vision and the nature of reality that transformation can occur. Both, Brunelleschi and Fontana, rather than distancing themselves from what they observe are engaging directly and viscerally with what is represented on the picture plane.

Damisch suggests another function of the role of mirrors is to undermine the logic that would associate perspective with the accurate representation of reality. In Brunelleschi's painting the sky was left unpainted. The 'actual' moving clouds (outside the sedentary cone of vision) thus were reflected onto the sky of the painting seen through the peephole. 
Damisch, The Theory of /Cloud/ (2002)

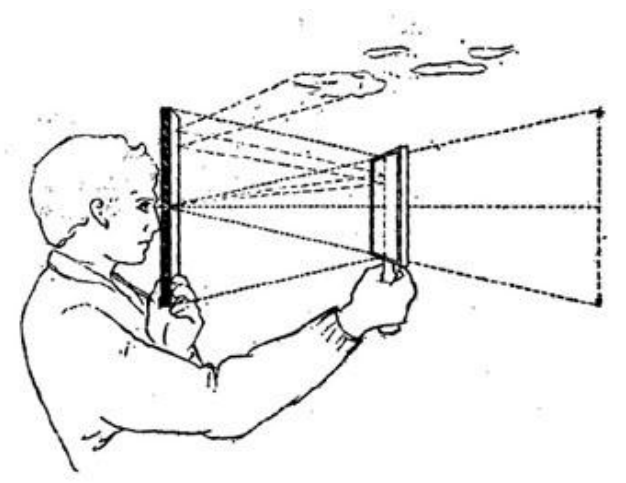

The unpainted sky and mirror was vital in order to sustain the illusion of seeing reality, because it meant that the clouds could move as they would if you were looking at the baptistery itself, rather than at a representation of it. However, that Brunelleschi had to leave the sky unpainted has the effect of revealing, very materially, the artificiality of perspective as a system. Perspective is unable to capture time and movement. In its attempt to stabilise vision, perspective reveals the transient nature of vision. This paradox is brought to the fore by juxtaposing the fluidity of the clouds, which disrupt the static rule-bound quality of the baptistery building. It is in this sense that the cloud decentres knowledge, operating " as the lack in the centre of that knowledge" (Krauss, 1992, p. 161). And it is through this crucial failure, "that painting understands its scientific aspirations - toward measurement, toward the probing of bodies, toward exact knowledge - as always being limited or conditioned by the unformed, which is unknowable and representable" (p. 161). Highlighting the artificial nature of perspective has the effect of challenging the narrowing of vision that perspective appears to insist on.

Using a framing device such as the grid as a technology of observation synthesises vision to produce the already seen. In contrast, Brunelleschi's play of mirrors, and of holes that pierce the canvas can be read as generative play and experimentation with the nature of vision and the nature of reality. Putting perspective into play can make us aware of our own blindness and incite us to new seeing. Damisch pushes this idea further so that Brunelleschi's painting "not only shows but thinks" (1995, p. 446). In my own research this has prompted me to (re)view research fragments (scribbled notes and diagrams, photographs, and the replaying of film) as thinking objects. Rather than approaching them as slices of the real, they become objects of encounter in which self and not-self are folded. Discarded data pieces and objects from the field that resisted categorisation become a fertile territory, where their intransigence "in the face of rule- or pattern-seeking propensities of conventional social science" (MacLure, 2006, p. 231) make me think again. The illegible forces me to enter unfamiliar and different spaces.

\section{Concluding thoughts}

Viewed through an organised frame, children are made legible through its ordering principles; and the way that they are constructed within that space is presented to our gaze "in an already composed state, already articulated" (Foucault, 1994, p. 252). Thus the child is already produced and being produced at the same time. Because this structure is established through procedure, it has a double effect where the observance of procedure also has the effect of producing the teacher/researcher. Adhering to observational procedure produces knowledge that keeps the observer within a disciplinary frame. At the same time as operating within a 
modernist scientific discourse of the norm and the rule, advocates of child observation have in some ways resisted this discourse, by invoking the naturalism of a more classical approach. By focussing the gaze firmly on the object, they can claim to produce more authentic knowledge founded in the object itself; this is how child observation as ritual attempts to mark itself as 'different' and thus as producing new knowledge. Yet, while rituals of child observation are often used in order to counter the regularisation of children, they have the effect of determining the spaces occupied by children. The Target Child grid, like Alberti's, constructs a spatial enclosure from which to view the child from a certain position. This is because rituals of child observation are not sufficiently critical of sight as a source of perceptive knowledge. While they acknowledge that looking can never be wholly innocent, they construct a framework to look through which elides the subjective and relational, by maintaining a distance between viewer and viewed. The child is something 'out there', an object that can be isolated within the frame; something that can be transcended. And so children continue to be produced through procedures that, by organising the gaze, frame the space of the observation, perpetuating a belief that children occupy worlds that we can both understand and go beyond (Cannella, 1997, p. 133).

Brunelleschi's mirror-play, in contrast, reminds us not only that we are folded into what we see, but also that any image (pictoral or verbal) is always lacking and any claims to certainty are illusory. The mirror here "becomes not just an duplicating but an enacting oracular device" (Stafford ,2001, p. 30) prompting us to meditate on what is absent and present in what we see. Irit Rogoff uses the idea of the 'curious eye' as a counterweight to the 'good eye'.

Curiosity implies a certain unsettling, a notion of things outside the realm of the known, of things not quite yet understood or articulated, the pleasures of the forbidden or the unthought, the optimism of finding out something one had not known or been able to conceive of before (2000, p. 32).

Although there is a trend towards less procedural methods of observing and documenting children in early years settings, this is taking place against a backdrop of increasing targets and milestones prescribed through centrally imposed early years curriculums. Unless we think more deeply about the underlying theoretical underpinnings of child observation there is a danger that documentation (often, in the U.K., now called children's 'learning journeys') continues to regulate and position the child. These 'learning journeys' bear traces of the Target Child method in their focus on the child as an individual whose actions are extracted from the complex relational social interactions that take place in the classroom. Adopting what initially appear to be more 'progressive' methods can continue to discipline and privilege the observing eye, especially when the background to these documents is the assessment of children in terms of their stage of development and to also audit a balanced coverage of curriculum areas. Putting art theory to work in order ward against complacency and to think harder about how and why we observe children might support a more experimental and self-conscious engagement with the observed. By privileging a more curious and thinking eye as opposed to a good eye that simply records, we might become more implicated ourselves in the observations we make. We might be able not only to reflect on the children's actions, but also our own. Instead of producing objective accounts of the other, we could perhaps be less fearful about 'mobilizing' our own subjectivity (Schratz \& Walker, 1995, p. 139) in order to generate of own theorybuilding. This more intense but less pre-scribed engagement children and their activity may open up spaces for us to talk about the uncertain and as yet unsaid. Here the aim is less about knowing the child better, and more about generating new, but shifting (and) to local 
knowledge(s) and projects that become part of a continuing dialogue between both practitioners, researchers, and the children themselves.

\section{Literature}

Adams, S. Alexander, E. Drummond, \& M. Moyles, J. (2004). Inside the Foundation Stage. Association of Teachers and Lecturers.

Alberti, L. B. (1966). On Painting. Connecticut: Yale University Press.

Alberti's Grid, Image, http://www.acmi.net.au/AIC/MAGIC MACHINES 1.html

Anning, A. \& Edwards, A. (2006). Promoting children's learning from birth to five: Developing the new early years professional, Sydney: MacGraw-Hill International.

Baxendall, M. (1972). Painting and Experience in Fifteenth-Century Italy. Oxford: O.U.P.

Brien, D. (2005). Robert Romanyshyn On Technology as Symptom \& Dream, http://www.cgjungpage.org/index.php?option=com content\&task=view\&id=683\&lte $\underline{\mathrm{mid}=40}$. (accessed, 13.09.2007)

Brunelleschi's experiment, image. www.hccs.cc.tx.us/.../Brunelleschi.html (accessed, 5.10.2007)

Bryson, N. (1988). The Gaze in the Expanded Field. In (Ed. Foster, H.) Vision and Visuality. Seattle: Bay Press.

Cannella, G. (1997). Deconstructing Early Childhood Education. New York: Peter Lang Publishing.

Cannella, G. \& Viruru, R. (2004). Childhood and Postcolonisation: Power, Education, and Contemporary Practice. London: RoutledgeFalmer.

Clifford, J. (1988). The Predicament of Culture. London: Harvard University Press.

Cosgrove, D. (1985). Prospect, perspective and the evolution of the landscape idea.

Transactions of the Institute of British Geographers, 10, 45-62

Crary, J. (1998). Techniques of the Observer. Massachusetts: MIT Press.

Dahlberg, G., Moss, P. \& Pence, A. (1999). Beyond Quality in Early Childhood

Education and Care. London: Falmer Press.

Damisch, H. (1995). The Origin of Perspective, MIT Press, Massachusetts.

Damisch, H. (2002). A Theory of /Cloud/: Toward a History of Painting. Translated by Janet Lloyd. Stanford: Stanford University Press.

Deleuze, G. (1988). Foucault. London: Athlone Press.

Deleuze, G. and Guttari, F. (1988). A Thousand Plateaus: Capitalism and schizophrenia. University of Minnesota.

Denzin, N. (1997). Interpretative Ethnographic Practices for the Twenty-First Century. California: Sage.

Duberry, F. \& Willats, J. (1972). Drawing Systems, London: Studio Vista.

Elkins, J. (1996). The Object Stares Back. San Diego: Harvest.

Fontana, L. Last Interview (members.aol.com/mindwebart3/page65.htm) (accessed 2006).

Foucault, M. (1994). The Order of Things. An archaeology of the human sciences. London: Routledge.

Geertz, C. (1993). The Interpretation of Culture. London: Fontana.

Hammersley, M. \& Atkinson, P. (1995). Ethnography. Principles in Practice. London: Routledge. Hockney, D. (2001). Secret Knowledge. London: Thames and Hudson.

Jenks, C. (2005). Culture. London: Routledge.

Krauss, R. (1992). ' The/CLOUD/" pp. 155-165. In Haskell, B. (ed) Agnes Martin, New York: Whitney Museum Of American Art.

Lather, P. (1993). 'Fertile Obsession: Validity After Poststructuralism', The Sociological Quarterly, 34(4), 673-693. 
MacLure, M. (2006). A demented form of the familiar': postmodernism and educational research. Journal of Philosophy of Education, 40(2), 1-17.

Panofsky, E. (1991). Perspective as Symbolic Form. New York: Zone Books.

Rogoff, I. (2000). Terra Infirma. London: Routledge.

Schratz, M. \& Walker, R. (1995) Research and Social Change, London: Routledge.

Sontag, S. (1979). On Photography, London: Penguin.

St. Pierre, E. (1997). "Nomadic inquiry in the smooth spaces of the field: a preface". Qualitative Studies in Education, 10(3), 365-383.

Stafford, B. M. (2001). "Revealing Technologies/Magical Domains." Devices of Wonder: From the World in a Box to Images on a Screen. Ed. Stafford, B. M. \& Terpak, F. Los Angeles: The Getty Research Institute.

Stronach, I., Garratt, D., Pearce, C., \& Piper, H. (2007). Reflexivity, the picturing of selves, and the forging of method. Qualitative Inquiry, 13, 179-203.

Sylva, K., Roy, C., \& Painter, M. (1980). Childwatching at Playgroup and Nursery School, London: Grant McIntyre.

Sylva, K., Melhuish, E., Sammons, P., Siraj-Blatchford, I. \& Taggart, B. (2004). Effective provision of pre-school education (EPPE) project: Final Report. London: DfES.

Trinh, T. Minh-ha (1991). When the Moon Waxes Red. London: Routledge.

Walkerdine, V, (1984). Developmental Psychology and the child-centred pedagogy: the insertion of Piaget into early education, in Eds. Henriques, J., Holloway, W., Urwin, C., \& Walkerdine, V. Changing the subject. London: Methuen. 